https://doi.org/10.48009/1_iis_2005_325-331

\title{
DESIGNING A STRATEGIC INFORMATION SYSTEMS PLANNING METHODOLOGY FOR MALAYSIAN INSTITUTES OF HIGHER LEARNING (ISP-IPTA)
}

\author{
Irny Suzila Ishak, Universiti Industri Selangor, irny@unisel.edu.my \\ Rose Alinda Alias, Universiti Teknologi Malaysia, alinda@utm.my
}

\begin{abstract}
This paper describes a Strategic Information Systems Planning (SISP) methodology designed to be appropriate for the organizational requirements of Malaysian Public Institutes of Higher Learning (PIHLs or IPTA in Malay Language). A Ministry of Higher Education was created in June 2004 to enable greater control and coordination over the activities of the 17 PIHLs, including ICT planning and implementation. Until late nineties, SISP formulation was an uncommon activity among Malaysian PIHLs. Thus, a methodology to guide SISP in PIHLs is highly timely. An ISP-IPTA methodology provides a systematic description of the tasks, steps, techniques and tools that can empower the Malaysian PIHLs to produce an SISP document without engaging external consultants. A draft methodology was documented through an analysis synthesis of existing SISP methodologies and assessed by SISP experts based on the criteria of suitability, accuracy, understandability, usability and completeness. The final ISPIPTA methodology document was produced based on their recommendations. A committee comprising ICT directors of all seventeen Malaysian PIHLs is currently using this document to develop an ICT Strategic Plan (ISP) blueprint that will guide ICT implementation in their respective universities.
\end{abstract}

Keywords: Strategic Information System Planning (SISP), Educational Institutions, Public Institute of Higher Learning (PIHL), SISP methodology, Malaysian Context

\section{INTRODUCTION}

Strategic Information Systems Planning (SISP) is a continuous planning activity that ensures Information and Communication Technology (ICT) implementation in an organization is aligned with business strategies, improves organizational process effectiveness, creates business opportunities and contributes to organizational competitiveness [18]. An SISP methodology is especially useful for the inexperienced SISP developer because it provides a systematic guideline to carry out the IS strategy formulation process. The main objective of this research was to extend from a business environment to a public higher education institution a well-validated SISP methodology. The purpose of this paper is to report the design of an SISP methodology that is appropriate for the context of Malaysian Public Institutions of Higher Learning (PIHLs).

The design was initiated based on an analysis of existing SISP methodologies generally used in business, as well as SISP methodologies specifically developed for the context of educational institutions. Lederer and Sethi [20] reported a study that ranked SISP methodologies commonly used in business in the following order: Business Systems Planning [8], PROPLANNER SISP Methodology [7], Information Engineering [14], and Method/1 [2]. 
Our ISP-IPTA design was based on the identification of the strengths of these methodologies. SISP methodology within the public educational institution context should highlight ICT strategies as a basis for cooperative arrangements, alliances and collaboration amongst the PIHLs. These features, however, were not evident in these methodologies as well as in those developed specifically for educational institutions such as UCLA [16], University of California at Berkeley [15] and Carleton University [17]. Thus, the purpose of this research was to determine how existing SISP methodologies could be adapted to design a guideline for SISP formulation in public educational institutions. The following sections address this problem.

\section{WHAT IS SISP METHODOLOGY?}

Methodology is generally a guideline for solving a problem, with specific components such as phases, tasks, methods, techniques and tools $[17,10]$. Methodology benefits managers by providing information to plan, review and control projects. Generally methodologies are comprised of the following four elements: providing an opinion of what needs to be solved, defining techniques on what has to be done and when to do it, advising on how to manage the quality of deliverables or products, as well as providing a toolkit to facilitate the process [17].

An SISP methodology can be viewed as an abstract system design that functions to transform organizational inputs (such as business strategy, assessment of current IS environment, and organizational influence) into an IS Strategic Plan as an output. When executing the SISP process, the abstract system design is applied in the context of multiple human activity systems (HAS) involving the SISP stakeholders (developers and clients) [10].

SISP methodologies can be categorized into two categories; namely, general and specific-tocontext methodologies. Three contexts were analyzed in the latter category; namely, business context, government context and educational context (Table 1). While there are numerous SISP methodologies, approaches and frameworks, the majority is oriented for commercial and production-based organizations, and is not suitable to guide SISP formulation in service-oriented industries and government [17]. The business strategy model and a university strategy model are different in terms of time frame, consensus, value system, customers and context [12]. Thus, business-context SISP methodologies are not suitable to guide SISP formulation in public educational institutions and government agencies because they focus primarily on the alignment of ICT strategies to the business objective of profits and competition. Government agencies and PIHLs focus on the formulation of ICT strategies to improve service delivery to the citizen and nation rather than profitability and competition $[1,9,13]$.

Although many SISP methodologies provide an overview of how to develop an SISP, the methods, techniques and tools to guide the SISP formulation process are not specified. The SISP initiation approach, the SISP team, and the set of tasks, activities and tools are not suited to the educational institution environment [9]. Thus, the primary objective of the ISP-IPTA Methodology design was to document objectives and tasks in every phase, as well as the methods and techniques that can be used to implement the tasks. The methods and techniques are complimented by an automated toolkit that that can facilitate the SISP formulation process [16]. 
Table 1. Categories of SISP Methodologies

\begin{tabular}{|c|c|c|c|}
\hline Category & Context & Methodology Name & $\begin{array}{l}\text { Methodology } \\
\text { Owner/Source (Year) }\end{array}$ \\
\hline \multirow[t]{4}{*}{ General } & \multirow[t]{4}{*}{ All } & $\begin{array}{l}\text { PROPLANNER Strategic Information } \\
\text { System Planning Methodology }\end{array}$ & $\begin{array}{l}\text { [7] Holland System Corp. } \\
\text { (1986) }\end{array}$ \\
\hline & & Method/1 & $\begin{array}{l}\text { [2] Andersen Consulting } \\
\text { (1985) }\end{array}$ \\
\hline & & Information Engineering (IE) & [14] James Martin (1982) \\
\hline & & Conceptual IS Strategy Framework & [6] Galliers (1993) \\
\hline \multirow[t]{3}{*}{ Specific } & \multirow[t]{3}{*}{ Business } & Business System Planning (BSP) & [8] IBM (1975) \\
\hline & & SISP Framework & $\begin{array}{l}\text { [20] Ward and Peppard } \\
(2002)\end{array}$ \\
\hline & & Information Systems Plan Methodology & [4] Cassidy (1998) \\
\hline Specific & Government & $\begin{array}{l}\text { Malaysian Public Sector ICT Strategic } \\
\text { Plan Guide }\end{array}$ & [13]MAMPU (2003) \\
\hline \multirow[t]{3}{*}{ Specific } & \multirow[t]{3}{*}{ IHL } & IT Strategic Plan Guide & [19] UCLA (1996) \\
\hline & & IT Strategic Plan & $\begin{array}{l}\text { [3] Carleton University } \\
(2001)\end{array}$ \\
\hline & & University of California at Berkeley & [15] McCredie (2000) \\
\hline
\end{tabular}

\section{WHY PUBLIC EDUCATIONAL INSTITUTIONS NEED AN APPROPRIATE SISP METHODOLOGY}

Public educational institutions in many countries (including Malaysia, Thailand, Myanmar, Russia, Republic of Estonia and Tanzania) report to a Ministry of Higher Education (MOHE). As part of public sector agencies, they are highly dependent on a system of bureaucracy to ensure the smooth running of government machinery and are governed by policies, guidelines, rules and regulations. The Malaysian Administrative, Modernization and Management Planning Unit (MAMPU) is a government agency that is responsible for coordinating the development of ISPs at all Malaysian government agencies to ensure that they support the Malaysian Public Sector ICT Vision. MAMPU published the Malaysian Public Sector ICT Guidelines Version 1.0 in August 2003 to guide SISP strategy formulation [13]. The complete design of our ISP-IPTA Version 1.0 was exhibited in the Malaysian Science \& Technology Expo in June 2003 and won a silver medal award for ICT category. There were many similarities between the two guidelines.

The cultural conflict within the context of Malaysian PIHLs gives rise to the need for an appropriate SISP methodology. The organizational culture of a public sector organization makes the structured phases, systematic activities and choice of instruments and tools within both guidelines highly attractive and beneficial, especially for the PIHL ICT directors who have limited knowledge and experience in SISP formulation. The ISP-IPTA methodology enables them to identify potential ICT applications (in IS strategies) and potential technology infrastructure (in IT strategies) that are complemented with appropriate IS/IT management strategies $[9,16]$. On the other hand, Malaysian PIHLs demand a greater amount of autonomy in their ICT implementation when compared to other public sector agencies. ISP-IPTA provides 
them the choice to determine to what extent they want to subscribe to the public sector ICT policies, strategies and guidelines.

\section{HOW WAS THE ISP-IPTA METHODOLOGY DEVELOPED?}

The study to formulate the ISP-IPTA methodology involved two main phases with eight subphases, which took 24 months to complete (Refer to Figure 1).

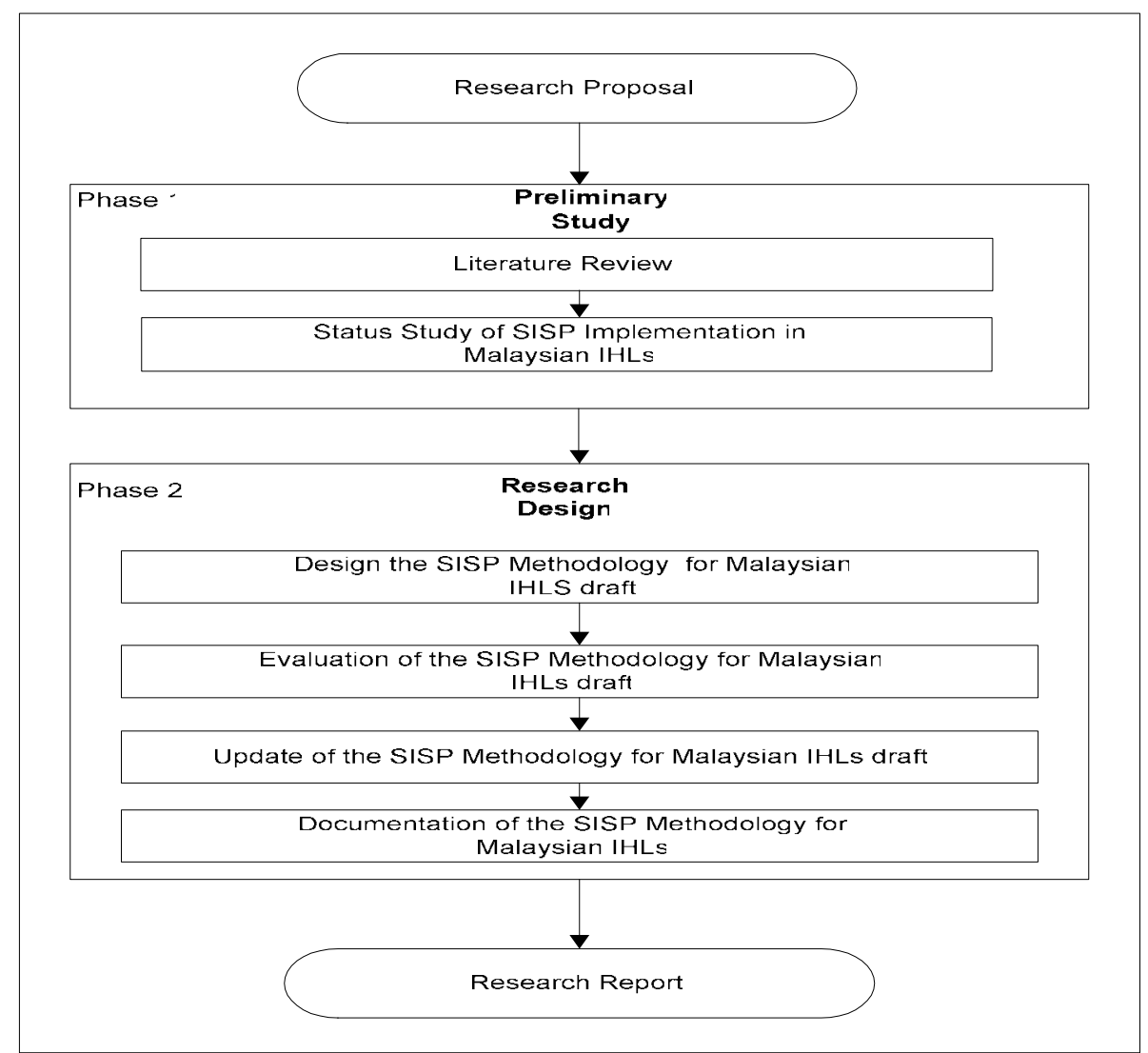

Figure 1. Research Design

The objective of the first phase was to understand the requirements of a specific SISP methodology for Malaysian PIHL context. The activities involved literature review and status study. Literature on relevant SISP concepts, SISP Methodologies, SISP techniques and toolkits were analyzed to identify common elements in an SISP methodology. A status study was conducted via questionnaires and interviews at seven Malaysian PIHLs that had or were currently implementing SISPs. The authors interviewed seven ICT Directors in Malaysian PIHLs in 2002 to understand critical issues faced by Malaysian PIHLs in implementing SISP. Two most critical issues faced by the ICT directors responsible for ICT implementation in these institutions were lack of expertise and lack of funding. Only four Malaysian public universities had an ICT blueprint, which they had to develop themselves when SISP consultants initially employed to undertake the responsibilities did not understand the unique organizational characteristics of PIHLs and applied general SISP methodologies that were incongruent with the organizational objectives of PIHLs [9]. Findings from the preliminary study in the first phase were used to design a draft ISP-IPTA methodology in the second phase. 
SISP experts to evaluate the draft were selected based on two critical requirements: first, they must be PIHL ICT Director, and secondly, they must have experience in formulating ICT strategies for various organizational contexts. The draft was evaluated on five criteria: suitability, accuracy, understandability, usability and completeness. The ISP-IPTA methodology was then revised based on the suggestions of these SISP experts. The following section describes the revised ISP-IPTA methodology

\section{ISP-IPTA METHODOLOGY FOR MALAYSIAN IHLS}

The ISP-IPTA Methodology consists of four main phases (Refer to Figure 2). The first phase is entitled "The Initial Phase of SISP Planning Process in IHLs." The objective of this phase is to define the SISP scope and the implementation plan for the SISP project. The importance of this phase is to ensure justification for the project, to monitor the change management and project formal acceptance. This phase is the most critical phase because it addresses the main problems identified in the status study, namely lack of funding and lack of expertise. Top management of the university and the MOHE must be convinced of the need for the SISP so that sufficient budget can be allocated. The team members must be properly trained on the SISP-IPTA methodology to enable them to become project champions.

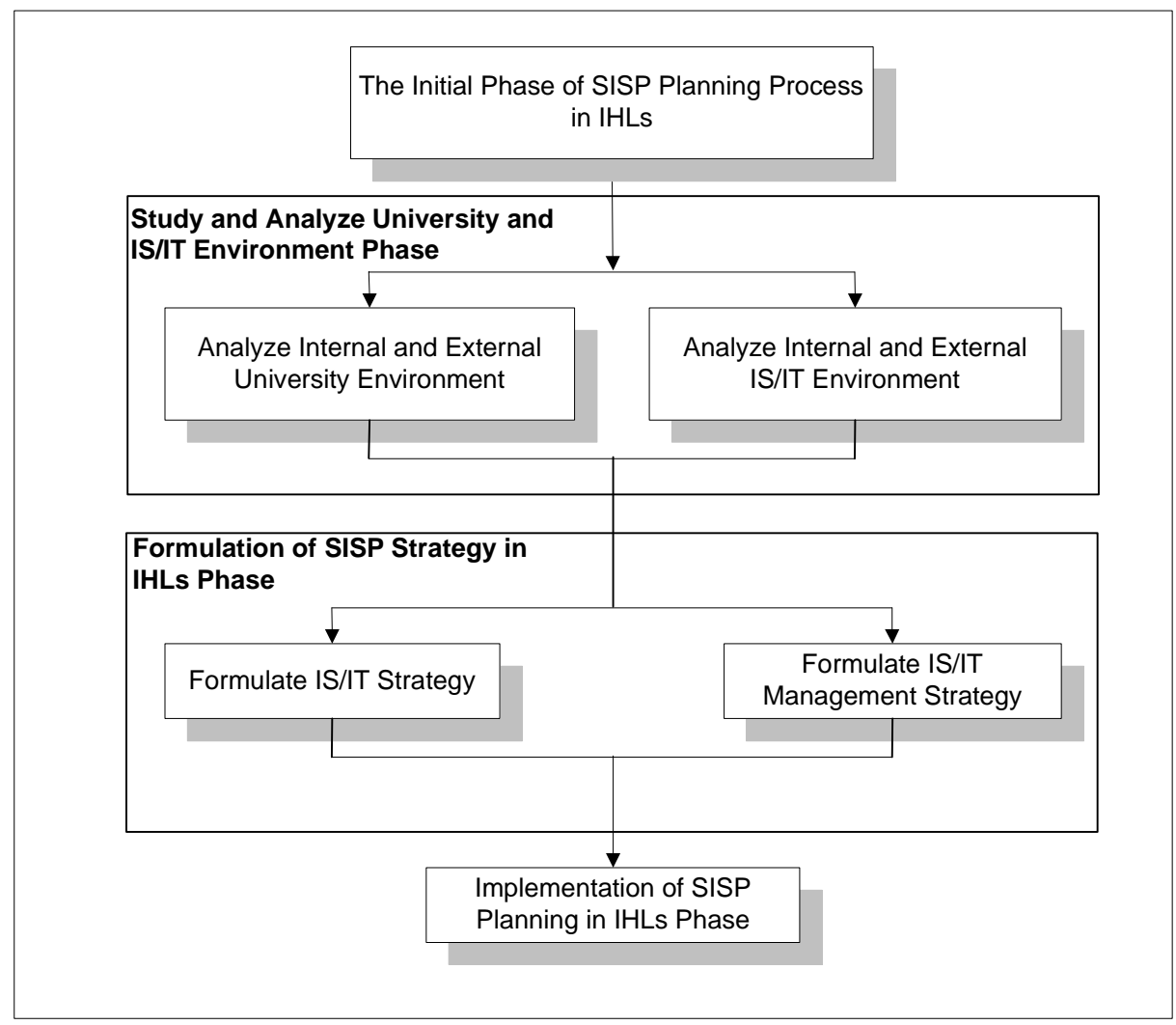

Figure 2. SISP Methodology for Malaysian PIHLs

The objectives of the analysis of the university and ICT environments in the second phase are to assess how ICT is currently supporting the university value chain, to identify the strategic drivers and capacity for change and to identify ICT opportunities. This phase is important to identify the 
strengths, weaknesses, opportunities and threats of the university and benchmark IS/IT status in the university $[5,16]$.

The objectives of ICT strategy formulation in the third phase are to prioritize the university activities to be supported by ICT and identify the university's future portfolio of ICT applications, to identify the appropriate applications development strategy, to formulate the IS service quality management strategies [1], to define the ICT policies, and to identify the financing strategy as well as other strategies related to ICT management. The objectives of the fourth phase are to draft the plan for change management, define project requirement, analyze cost and benefit, develop an action plan, obtain top management approval, review the SISP plan and manage the SISP implementation. An automated toolkit comprised of various SISP techniques and tools supports the SISP formulation process. These include SWOT Analysis, Five Forces Model, CSF Analysis, Value Chain Analysis, Application Portfolio Matrix and Internal Benchmarking $[5,11,16]$.

\section{RESULTS}

The ISP-IPTA methodology is currently being used by the Malaysian PIHL ICT Directors Committee to guide the formulation of SISP. The main strategic thrusts of the study were to focus on synergy of ICT implementation, utilizing a collaborative approach to align the Malaysian PIHL ICT vision with the vision of the Ministry of Higher Education. The effectiveness of the ISP-IPTA implementation was influenced by the cultural conflict between the requirement for bureaucracy and the need for creative autonomy.

Initially, the SISP participants appreciated the set of systematic and structured guidelines, activities, instruments, tools, and techniques provided by the methodology. However, while the majority stakeholders (both developers and participants) appreciated the availability of the toolkit, a number of them felt that the guidelines and toolkit were too restrictive and constraining. The ISP-IPTA prescriptive nature prevented the stakeholders from exploring other perspectives and approaches in the strategy formulation process. The automated SISP toolkits could only be used when all the stakeholders were familiar and comfortable with the SISP strategy formulation process in the ISP-IPTA methodology.

\section{CONCLUSIONS}

The main lesson learned from the implementation of the ISP-IPTA is that a methodology cannot be used in a prescriptive manner. Instead, it must be employed within a paradigm of it being an abstract system design that enriches the SISP process and empowers the participants by providing a set of guidelines and toolkit. The existence of multiple human activity systems within the Malaysian PIHL context implies that the ISP-IPTA methodology must be adapted according to the experience of the stakeholders involved in the SISP process as well as the PIHL organizational culture. The ISP-IPTA methodology can also be used as a guideline for other countries where the government has a Higher Education Ministry to monitor ICT implementation in educational institutions. It is also useful for other similar automated strategy formulation toolkits. 


\section{REFERENCES}

1. Alias, R.A. \& Abdul Rahman, A. (2001), Understanding IS Services, UNITEN, Malaysia: International Conference on Information Technology and Multimedia (ICIMU 2002).

2. Andersen Consulting. (1992). Foundation Method/1. Version 9, Arthur Andersen and Co.

3. Carleton University (2000). At the Crossroad. Information Technology Strategic Planning Report and Presentation. http://www.carleton.ca/itsp/

4. Cassidy. A. (1998). A Practical Guide to Information Systems Strategic Planning. Boca Raton, Florida: St. Lucie Press

5. Clarke, R. (1992). Strategic Information Systems Theory: Retrospect and Prospect. Bled, Slovenia: International Conference on Information Systems and Organisations.

6. Galliers, R. D. (1993). Towards a Flexible Information Architecture: Integrating Business Strategies, Information Systems Strategies and Business Process Redesign." Journal of Information Systems, 3, 193-213.

7. Holland Systems Corporation. (1986) Strategic Systems Planning, document \#M015404861986, Ann Arbor, MI, 1986.

8. IBM Corporation (1975). Business Systems Planning -Information Systems Planning Guide, publication \#GE20-0527-4.

9. Ishak, I.S. (2004). Merekabentuk Metodologi Perancangan Strategik Sistem Maklumat di IPTA Malaysia (Designing a Strategic Information Systems Plan for Malaysian IHLs). UTM, Malaysiai: Universiti Teknologi Malaysia Unpublished M. Sc. Thesis.

10. Klein, H. K. \& R. Hirschheim. (2001). Choosing Between Competing Design Ideals in Information Systems Development, Information Systems Frontiers, 3(1), 75-90.

11. Lederer, A. L. \& Sethi, V. (1988). The implementation of strategic information systems planning methodologies, MIS Quarterly, 12(3), 445-461.

12. Lerner, A. L. (1999), A Strategic Planning Primer for Higher Education. http://www.des.calstate.edu/strategic.html

13. MAMPU (2003). The Malaysian Public Sector ICT Strategic Plan Guide. Kuala Lumpur: Malaysian Administrative Modernization \& Management Planning Unit.

14. Martin, J (1982). Strategic Data Planning Methodologies. New York: Prentice Hall.

15. McCredie, J. W. (2000). "Planning for IT in Higher Education: Its not an oxymoron," Educause Quarterly, (4).14-21.

16. Miskon, S. (2001).Pembangunan Prototaip Alatbantu Perancangan Strategik Sistem Maklumat. (Strategic Information Systems Planning Automated Toolkit), UTM, Malaysia: Universiti Teknologi Malaysia Unpublished M. Sc. Thesis.

17. Robson, W. (1997). Strategic Management and Information Systems: An Integrated Approach. London: Pitman Publishing.

18. Rogerson, S. \& Fidler, C. (1994). Strategic Information Systems Planning: Its Adoption and Use, Information Management and Computer Security, (2),1-7.

19. UCLA IT Planning Project (1996). Key issues in Information Technology in Higher Education. Coopers and Lybrand Consulting.

20. Ward, J \& Peppard, P. (2002). Strategic Planning for Information Systems. England: John Wiley and Sons. 